\section{Glycemic Index of Rajma Bean (Phaseolus vulgaris) and Guar (Cyamopsis tetragonoloba) Incorporated Noodles: A Volunteers Study}

\section{Abstract}

Context: Diabetes mellitus is one of the non-communicable disorders, affecting over $2.8 \%$ of the World's population. As noodles are becoming popular diets now-a-days and is categorized as high glycemic index (GI) product this is not recommended for diabetics.

Objective: Current study focuses on the influence of low-GI ingredients on noodle GI.

Methods: On basis of preliminary studies, rajma flour, whole guar and guar seed powder incorporated noodles were selected for the study. Noodles were prepared, dried and cooked just before the test. 15 healthy and 10 diabetic subjects were chosen for the study. All the subjects were healthy except for diabetes. All the subjects were given a test food after an overnight fasting. Fasting blood glucose was measured before the test. Blood glucose levels were measured at different time intervals.

Results: Results of the study indicated that with different ingredients incorporation there was significant difference in the GI of the noodles. Noodles with added ingredients showed significant reduction of GI value of 49,32 and 25 with rajma, whole guar and guar seed powder respectively compared to control noodles.

Conclusions: Study spotlights on the use of these health's beneficial ingredients in the noodle processing and its effect on health. The developed noodles may be included in the diet of diabetic patients.

Keywords: Rajma; Guar; Guar seeds; Glycemic index; Glycemic load; Diabetes Mellitus

\section{Srinivasan Bharath Kumar, Pichan Prabhasankar \\ Flour Milling Baking and Confectionery Technology Department, CSIR-Central Food Technological Research Institute, Mysore 570 020, India}

\section{Corresponding author:}

Pichan Prabhasankar

\section{झ psankar@cftri.res.in}

Flour Milling Baking and Confectionery Technology Department, CSIR-Central Food Technological Research Institute, Mysore 570 020, India

Tel: 91-821-2517730

Fax: 91-821-2517233

\section{Introduction}

Low glycemic index ingredients are those, which digest slowly and also release glucose into the blood gradually during absorption. This slow releasing property of the ingredients is a positive indicator in diet management of the diabetic individuals [1]. Majority of the legumes like pea, lentil, rajma, chickpea and also some of the high fiber vegetables have a similar effect on the blood glucose after ingestion. Soluble and insoluble dietary fibers are polysaccharides which pass the normal digestion process [2]. Rajma or Kidney bean is a legume with higher fiber content. Guar or Cluster bean is the basic ingredient in the production of guar gum, isolated from the mature seeds of guar pods. The isolated guar gum is widely used in many industries as thickening agent, binder and so on. These low Gl ingredients have an effect on lowering the $\mathrm{Gl}$ because dried beans has an impact on lowering postprandial blood glucose and also factors like high fiber and enzyme inhibitors [3]. Glycemic response to a portion of food is influenced by several food factors like nutrient composition, energy density, organoleptic quality of foods etc. Glycemic load (GL) of a food product is an amount, which is the result of rise in blood glucose of a person after consuming the food. GL is based on GI of the foods. GL is the product of a food's total carbohydrate content and GI of the same food divided by hundred [4].

Noodles are classified under high GI foods with GI over 75. This is why it is not recommended for diabetics. Noodles with low GI ingredients may be beneficial not only for diabetic individuals but also for the healthy individuals to maintain their normal health. 
Noodles prepared with these ingredients have improved textural properties and also acceptable sensory qualities [5].

In the present study it is aimed to assess the influence of rajma, guar (as a whole) and guar seeds on GI of noodles by conducting a study on healthy, as well as diabetic individuals. As these ingredients are used in day to day diet, a noodle product is designed based on these low GI ingredients with potential benefit for the people in need. It also helps in diversifying the diet pattern as some of the people are reluctant to consume these ingredients in their original form.

\section{Methodology}

\section{Sample preparation}

Noodle samples were prepared according to the optimized results obtained for these low $\mathrm{GI}$ ingredients. On the basis of the preliminary results, $20 \%$ of rajma (Phaseolus vulgaris), $10 \%$ of guar (Cyamopsis tetragonoloba) and $7.5 \%$ of guar seed powder was incorporated to the noodles. Noodles were prepared following the method of Bharath Kumar and Prabhasankar [5], in brief flours were blended together to a uniform mixture and dough was prepared adding required amount of water in the dough maker attached to the noodle making machine (Imperia Restaurant-RM 220, Italy). Dough was rested for $15 \mathrm{~min}$. Later, it was sheeted to desired thickness and cut into noodles using cutter. Prepared noodles were packed and stored at room temperature $\left(27^{\circ}-30^{\circ} \mathrm{C}\right)$ for further study.

\section{Chemical composition}

Noodles were analysed for protein and fat content according to the AOAC standard methods [6]. Micro-kjeldahl method was used to determine nitrogen content and soxhlet extraction method was used to determine fat content in the noodles. In order to calculate protein content from nitrogen determination a conversion factor 6.25 was used. Carbohydrate content in the noodles was calculated by difference.

\section{Food preference ratings}

Food pleasantness was rated after initial tasting. All ratings were made on general nine point hedonic scale from 1:"Dislike extremely" to 9: "Like extremely", determining their preference, choosing among three sensorial descriptors used by panelists namely; strand quality, aroma and taste. Results obtained from the study were tabulated and the preference of the consumers on the sample was recorded.

\section{Selection of participants for the study}

Fifteen healthy subjects ( 10 Men, 5 Women) and ten diabetic subjects (6 Men, 4 Women) were selected for the study, considering their previous health history. All the diabetic subjects were with moderate diabetes (Type 2 diabetes) with the fasting blood glucose levels in the range of 7.1-8.4 mmol/l. Healthy participants were non-smokers, not using any medicines, not on any therapeutic diet, no recent weight loss or gain $(>2 \mathrm{Kg}$ ) over the previous three months, had regular eating habits (morning breakfast, afternoon lunch and night dinner), fasting blood glucose levels were between 4-5.9 mmol/l, no family history of diabetes and celiac disease. Subjects having fasting blood glucose level higher than $5.9 \mathrm{mmol} / \mathrm{l}$ and BMI more than 24.5 were excluded for the study. In the case of diabetic subjects, onset of diabetes with minimal symptoms at the age of $\geq 34$ years and mean duration of diabetes was three years, which was uniform. All the diabetic subjects were not having history of ketosis. They were not on any medication other than similar oral hypoglycemic agents (Metformin) as prescribed by the physician, to whom they were regularly consulting. Subjects with severe diabetes were excluded for the study. Institutional Human Ethical clearance was obtained from the University of Mysore, Mysore for commencement of the study (Ref. no. IHEC-UOM No.99 PhD/2014-15). Consent was obtained from all the subjects before the study, stating the importance of the study and informing the harmlessness of the study with no effect on the normal health. Mean $\pm S D$ age of healthy subjects was $25 \pm 2$ years and for diabetic subjects it was $40 \pm 3$ years. Body weight and body mass index (BMI) averaged to $60.3 \pm 8.1 \mathrm{Kg}\left(\mathrm{BMI} 22 \pm 1.5 \mathrm{Kg} / \mathrm{m}^{2}\right.$ ) and $70.1 \pm 4.2 \mathrm{Kg}\left(\mathrm{BMI} 24 \pm 1.6 \mathrm{Kg} / \mathrm{m}^{2}\right)$ for healthy and diabetic subjects respectively. Glycosylated heamoglobin $(\mathrm{HbA} 1 \mathrm{C})$ of the diabetic subjects was in the range of $6.5-8.8 \%$ with an average of $7.7 \%$ indicating the level of diabetes in the participants. Characteristics of the participated subjects were given in (Table 1a) and (Table 1b) for healthy and diabetic subjects respectively.

\section{Test meal}

White bread served as a reference food in identifying $\mathrm{Gl}$ of the noodles as the $\mathrm{Gl}$ of the white bread is considered to be 100 . T. Durum noodles and other low GI noodles were prepared freshly before the test. To enhance the palatability of the noodles salt and non-starch spice mix were added while cooking. Nutritional composition of the test meal is given in (Table 2a). On the basis of sensory and product quality characteristics, $20 \%$ rajma, $10 \%$ guar and $7.5 \%$ guar seed powder incorporated noodles were taken for the study involving volunteers with finger prick blood glucose analysis.

\section{Diet modification for subjects}

Ten stable diabetics of both genders were included in this study. They were provided with brown bread to replace their usual breakfast, chapati for lunch and dinner, with some low carbohydrate vegetable preparations as accompaniments. This diet pattern was followed during the study period to minimize the errors in the results. On the day of test the hypoglycemic agents were stopped to determine the exact effect of the low GI noodles on the blood glucose levels. In case of the healthy subjects there was no significant diet modification except for the exclusion of some high carbohydrate and fat foods during the study. Both of the subjects were given $T$. durum noodles and low Gl ingredient incorporated noodles at different days. Experiment was conducted on three non-successive days involving volunteer. On the first day, subjects consumed white bread ( $50 \mathrm{~g}$ carbohydrates) considered to be a standard test food. On the second day, they were given cooked $T$. durum noodles ( $50 \mathrm{~g}$ carbohydrates) and the last day they ingested cooked low $\mathrm{GI}$ noodles (50 g carbohydrates) details of the study plan is given in (Table $2 b$ ). 
Table 1a: Characteristics of participated healthy subjects.

\begin{tabular}{|c|c|c|c|c|}
\hline Subjects & Sex & Age (Years) & Fasting blood glucose \\
(mmol/l)
\end{tabular}

Table 1b: Characteristics of participated diabetic subjects.

\begin{tabular}{|c|c|c|c|c|c|c|c|}
\hline Subjects & Sex & Age (Years) & BMI $\left(\mathrm{Kg} / \mathrm{m}^{2}\right)$ & $\begin{array}{l}\text { Fasting blood } \\
\text { glucose }(\mathrm{mmol} / \mathrm{l})\end{array}$ & $\begin{array}{l}\text { Duration of } \\
\text { diabetes (in } \\
\text { years) }\end{array}$ & HbA1C (\%) & $\begin{array}{l}\text { Hypoglycemic } \\
\text { agents }\end{array}$ \\
\hline 1 & $\mathrm{~F}$ & 35 & 23.1 & 7.1 & 3.0 & 6.8 & Metformin \\
\hline 2 & $\mathrm{~F}$ & 37 & 20.9 & 7.6 & 2.5 & 7.5 & Metformin \\
\hline 3 & $\mathrm{~F}$ & 38 & 25.4 & 7.4 & 4.5 & 7.9 & Metformin \\
\hline 4 & $\mathrm{~F}$ & 40 & 24.8 & 7.8 & 3.0 & 7.6 & Metformin \\
\hline 5 & M & 42 & 25.2 & 7.6 & 3.0 & 6.5 & Metformin \\
\hline 6 & $M$ & 41 & 24.2 & 7.5 & 4.0 & 8.8 & Metformin \\
\hline 7 & $M$ & 43 & 26.2 & 8.1 & 3.0 & 8.2 & Metformin \\
\hline 8 & M & 39 & 25.9 & 8.4 & 2.5 & 7.9 & Metformin \\
\hline 9 & $M$ & 41 & 24.5 & 7.5 & 3.0 & 7.5 & Metformin \\
\hline 10 & M & 43 & 26.4 & 7.7 & 3.5 & 7.8 & Metformin \\
\hline Mean $\pm S D$ & - & $39.9 \pm 2.6$ & $24.7 \pm 1.7$ & $7.7 \pm 0.4$ & $3.2 \pm 0.6$ & $7.7 \pm 0.7$ & - \\
\hline
\end{tabular}

Table 2a: Diet composition.

\begin{tabular}{|c|c|c|c|}
\hline Food & \multicolumn{3}{|c|}{ Composition } \\
\hline 1 & 11.5 & 2.9 & Carbohydrate by difference (\%) \\
\hline 2 & 15.6 & 3.5 & 81.3 \\
\hline 3 & 12.1 & 2.2 & 75.4 \\
\hline 4 & 19.2 & 2.5 & 79.2 \\
\hline
\end{tabular}

1-T. durum noodles, 2-Noodles with rajma, 3-Noodles with guar and 4-Noodles with guar seeds

Table 2b: Diet plan for the study (healthy and diabetic individuals).

\begin{tabular}{|c|c|}
\hline Days & $\begin{array}{c}\text { Foods given } \\
\text { (50g carbohydrates portion) } \\
\text { Day 1 }\end{array}$ \\
\hline Way 3 & T. durum noodles \\
\hline Day 5 & Low GI noodles* \\
\hline
\end{tabular}

* Low GI noodles were given at different days with the interval of 1-2 days

\section{Analysis}

Blood glucose levels were measured in fifteen healthy subjects and ten diabetic subjects. The study was conducted after a 12 $h$ fasting. The foods were given between 9:00 AM and 10:00AM and were eaten over 15 min. Fingerprick blood samples were taken using Accu-Chek Active (Roche Diagnostics India Pvt. Ltd.), method of testing as per the manufacturer, with the blood sampling over the test strips provided and measuring blood glucose level with the instrument supplied. Fasting blood glucose levels were recorded for the subjects. For healthy individuals measurement was carried out at 15, 30, 45, 60, 90 and $120 \mathrm{~min}$. In case of diabetic subjects, measurements were taken at 30,60 , $90,120,150$ and $180 \mathrm{~min}$ after taking $50 \mathrm{~g}$ of carbohydrate in the form of $T$. durum noodles and low $\mathrm{Gl}$ ingredient incorporated noodles. To identify the $\mathrm{GI}$ of the noodles results were compared with $50 \mathrm{~g}$ white bread values. Volunteers were allowed to drink 150-300 $\mathrm{ml}$ of water depending on the food consumed during the study. The GI was calculated following the procedure of Wolever 
et al [7]. These obtained values were compared with the GI of the ingredients from the literature. GL value of the food was calculated by using the obtained GI values of the samples. GI and GL of the samples were calculated using the equations below:

$\mathrm{GI}=\frac{\text { Incremental area under the blood glucose response curve of a test food }}{\text { Incremental area under the blood glucose response curve of a standard food }} \times 100$

$\mathrm{GL}=\frac{\text { Total carbohydrates per } 100 \mathrm{~g} \text { of sample X Glycemic index of the sample }}{100}$ 100

\section{Statistical analysis}

The results are expressed as mean \pm SD unless otherwise stated. Analysis of variance (ANOVA) was used to determine the statistical significance of difference between the samples. To simplify the expression of the results, only significant differences were systematically recorded in the text and tables incorporating the method used by Winer [8] and Duncan [9]. Postprandial differences were assessed by determining the peak change and the area under the incremental curve above fasting level of glucose.

\section{Results}

Characteristics of the subjects are given in (Table 1a) and (Table 1b). According to the results all the healthy subjects were in the age range of 21-29 years and with BMI 20.9-24.1. Fasting blood glucose was in the range of $4.4-5.5 \mathrm{mmol} / \mathrm{l}$. In case of diabetic subjects, age and BMI was in the range of 35-43 years and 20.926.4 respectively. Fasting blood glucose level was in the range of 7.1-8.4mmol/l.

Preference ranking test of the prepared noodles was carried out with nine point hedonic scale. Results of the overall quality scores were represented as percentage in Fig.1. Later the noodles were taken for the test with the volunteers.

Noodles were given to the healthy subjects to determine the GI of the noodles. GI and GL of the noodles are calculated and are given in Table 3 . The blood glucose response curves after consumption of noodles are shown in (Figure 2A) and (Figure 2B) for healthy and diabetic subjects respectively. In healthy subjects, there was a quick rise in blood glucose concentration and peak appeared in $30 \mathrm{~min}$ for white bread and $T$. durum noodles. Whereas, for low $\mathrm{Gl}$ ingredients incorporated-noodles peak was at $45 \mathrm{~min}$ and also slow decline was observed compared to other noodles. In case of diabetic subjects there was a gradual increase and also gradual decline in blood glucose after consumption of low GI ingredient-incorporated noodles. Whereas, for T. durum noodles there was a rapid increase in the blood glucose curve shown in (Figure 2B). There was a significant difference between the samples $(p \leq 0.05)$. GL of the noodles significantly reduced with lower carbohydrate content in the product shown in (Table 3). GL was reduced from 59 to 28 after the incorporation of low $\mathrm{Gl}$ ingredients to the noodles.

\section{Discussion}

The main purpose of the study was to determine the glycemic response of the low GI ingredients incorporated - noodles.
Results of the study indicated that all the healthy subjects had fasting blood glucose level within the normal range $(<5.9 \mathrm{mmol} / \mathrm{l})$ and also all the diabetic subjects had moderate diabetes. As far our knowledge goes, this is the first study reported in literature where, low Gl ingredients like rajma and guar were incorporated to the noodles to aid and widen the diet pattern of the diabetics.

The participants came up with positive feedback regarding delectability of the noodles served. Results from the Hedonic test (Figure 1) indicate that overall quality of all the given noodles were marked "Like Very much" by the participants. T. durum noodles scored above $93 \%$ followed by noodles with guar $(90 \%)$, rajma $(80 \%)$ and guar seeds (63\%). As the participants like the noodles, it also has direct impact on the food intake. Some of the earlier studies also analysed the effect of liking of food on the eating and their blood glucose pattern $[10,11]$.

With the consumption of low GI noodles there was a reduction in the incremental area under the curve compared to $T$. durum noodles. The rise in blood glucose levels for low GI ingredient incorporated noodles in healthy subjects points out the slow release property of the noodles due to the presence of legumes and high fiber ingredients [12]. Previous studies indicated the effect of rajma on blood glucose levels of the healthy subjects, with the consumption of cooked rajma seeds there was a decrease in postprandial blood glucose rise compared to glucose (Standard), also the peak was observed at $45 \mathrm{~min}$ for rajma sample [13]. In another study, a therapeutic diet was formulated using rajma with other legumes and given for 30 normal female subjects and noticed a decrease in the GI of the diets [14]. In an in vitro analysis of the pea flour and chickpea based noodles also showed a decrease in the available starch and rapidly digestible starch $[5,15]$. Reduction in postprandial blood glucose level in healthy subjects with the inclusion of chickpea bread in their breakfast is also a supporting evidence for the reduction in GI with the incorporation of legumes in the noodles [16]. According to the results obtained, $\mathrm{Gl}$ of the noodles were as follows; white bread $>T$. durum noodles>rajma noodles $>$ guar noodles $>$ guar seed noodles. Cereal and pulse fiber had a significant inverse association with risk of type 2 diabetes [17]. Guar is a superior source of soluble dietary fiber, known as galactomannan. Galactomannan has a hypoglycemic effect supported by previous studies [18], where bread was prepared with guar galactomannan and was observed reduction in starch digestibility of these breads. A novel chickpea based food is developed in an earlier study as it is considered to be valuable dietary sources of slowly digestible starch, a form of starch that is considered beneficial to health since it results in relatively lower postprandial blood glucose levels compared to high GI foods [19].

Furthermore, in diabetic subjects there was a reduction in incremental blood glucose curve when compared to $T$. durum noodles (Figure 2B). This may be attributed towards the presence of high protein and fiber content in the noodles. Increase in the protein content in the noodles has a positive effect on reducing postprandial blood glucose levels by increasing insulin sensitivity $[20,21]$. Fiber aids in slow release of glucose to the blood during absorption $[22,23]$.

The GL of food is an estimation of how much the food will elevate 


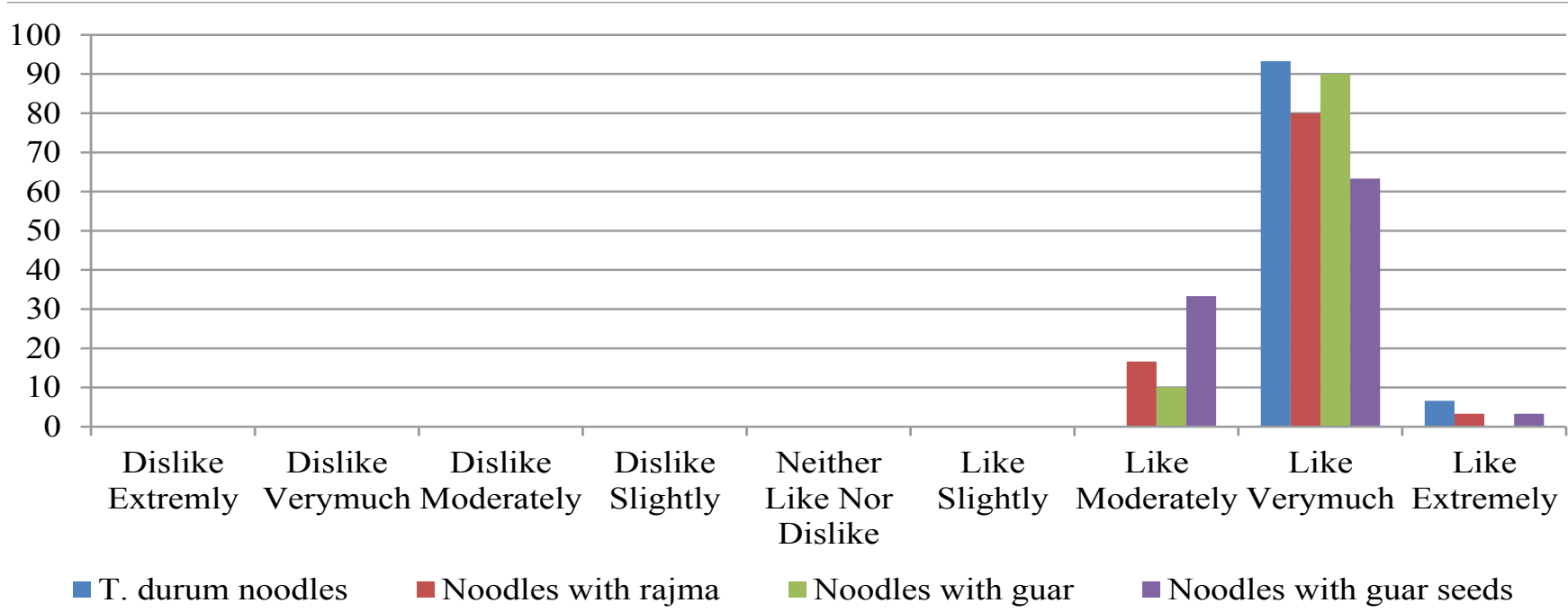

Figure 1 Preference ranking test of the noodles (Overall quality).
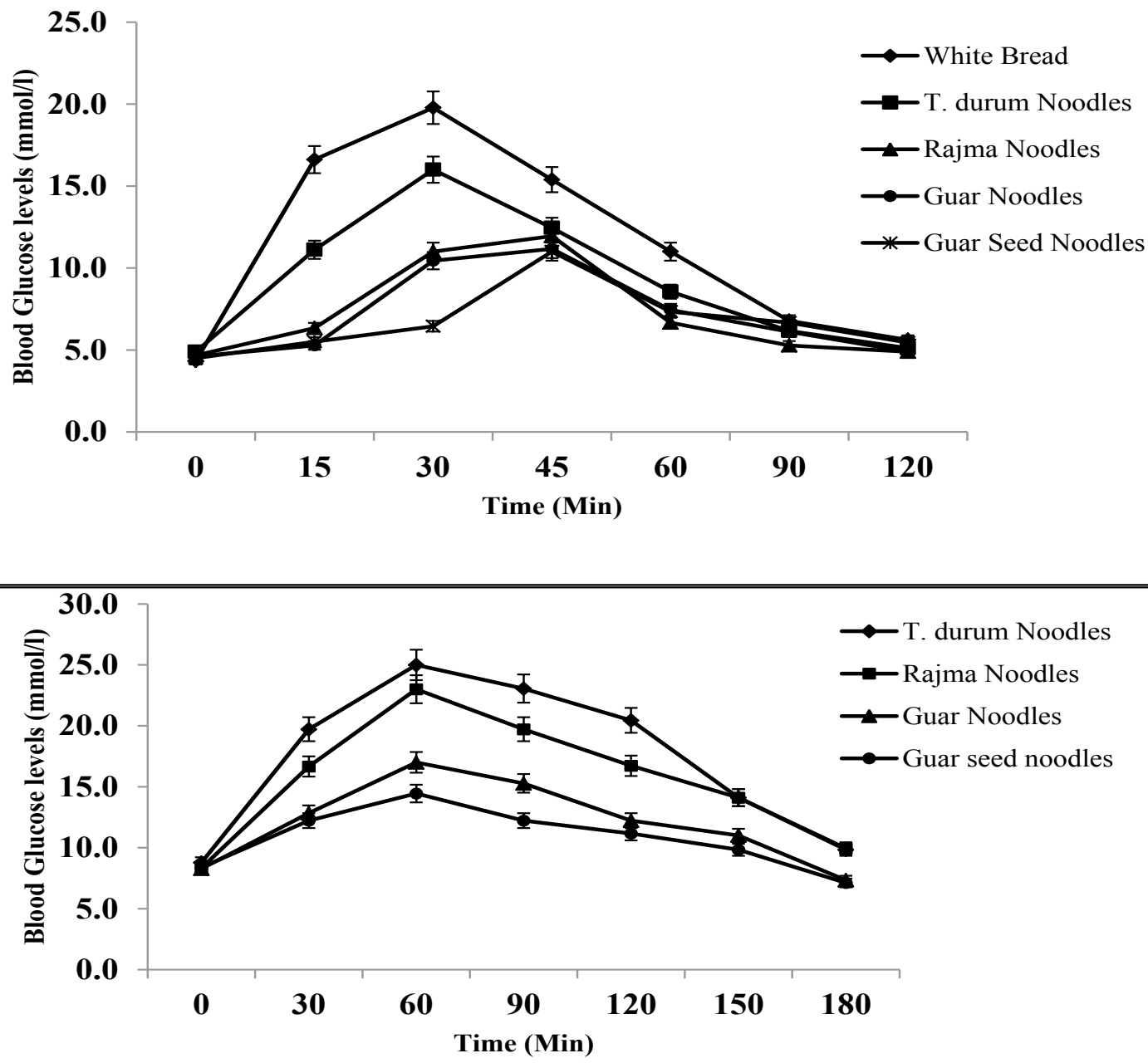

Figure 2

Blood glucose levels of $A$ : Healthy subjects and B: Diabetic subjects as influenced by $50 \mathrm{~g}$ carbohydrate portion of standard and test samples $(p \leq 0.05)(A-n=15$ and $B-n=10)$ 
Table 3: Glycemic Index and Glycemic Load of the noodles (per 50g carbohydrates portion).

\begin{tabular}{|c|c|c|}
\hline Foods & $\begin{array}{c}\text { Glycemic Index (Mean } \\
\pm \text { SD) }\end{array}$ & $\begin{array}{c}\text { Glycemic Load (Mean } \\
\pm \text { SD) }\end{array}$ \\
\hline White Bread & $100.0^{\mathrm{d}} \pm 5.0$ & $50.0^{\text {cd }} \pm 2.0$ \\
\hline T. durum Noodles & $73.0^{\mathrm{c}} \pm 4.0$ & $59.1^{\mathrm{d}} \pm 2.5$ \\
\hline Rajma Noodles & $52.9^{\mathrm{b}} \pm 9.0$ & $39.7^{\mathrm{b}} \pm 3.5$ \\
\hline Guar Noodles & $46.2^{\mathrm{a}} \pm 8.0$ & $36.5^{\mathrm{b}} \pm 2.0$ \\
\hline Guar Seed Noodles & $40.4^{\mathrm{a}} \pm 6.0$ & $28.6^{\mathrm{a}} \pm 3.0$ \\
\hline
\end{tabular}

a person's blood glucose level after eating it. Consumption of one gram of glucose will be a reason to elevate the blood glucose approximates for one unit of GL [24]. There was an increase in the protein content in all the samples as the low GI ingredients selected were rich in protein. Protein has a direct relationship with reduction in $\mathrm{Gl}$ of the food, with altering the insulin sensitivity of the subjects. GI of the sample is directly proportional to the GL of the samples. This can be attributed to reduced GL with the reduction in $\mathrm{Gl}$. Consumption of high $\mathrm{Gl}$ and high $\mathrm{GL}$ foods can be the risk factors for type 2 diabetes [25].

Among all the samples, guar seeds- incorporated noodles showed improved hypoglycemic effect compared to other noodles, this may be because of the galactomannan present in the guar seeds [18] and also increase in the protein content of about 33\% compared to control noodles, which helps to sensitize the insulin response of the subjects for the consumed foods [26]. It is evident from the previous studies that replacing high $\mathrm{Gl}$ carbohydrates with low GI forms will improve glycemic control among individuals on insulin treatment and also will reduce hypoglycemic incidents [27].

\section{Conclusion}

Study focuses on the use of these health beneficial ingredients in the noodle processing, as some of the consumers are reluctant to eat these in their native/original form. It is evident from the study that, noodles with low GI ingredients have a positive effect on the blood glucose levels was evident by this study. GI of the noodles reduced significantly from 73 to 40 conducted on healthy subjects. Reduction in $\mathrm{Gl}$ is because of the dietary fiber content, especially soluble dietary fiber. Among these ingredients guar seed incorporated noodles showed less GI and GL by improved hypoglycemic effect diabetics. These noodles can be beneficial for diabetic individuals because of reduced $\mathrm{Gl}$ and can widen the diet pattern. Slow glucose release property of the noodles helps in reducing rapid increase in blood glucose levels after ingestion of foods and also increases the insulin sensitivity in the diabetic individuals. 


\section{References}

1 Goni I, Garcia-Alonso A, Saura-Calixto FA (1997) Starch hydrolysis procedure to estimate glycemic index. Nutr Res 17: 427-437.

2 Goni I, Valentin-Gamazo C (2003) Chickpea flour ingredient slows glycemic response to pasta in healthy volunteers. Food Chem 81: 511-515.

3 Chung $H$, Liu Q, Pauls KP, Fan MZ, Yada R (2008) In vitro starch digestibility, expected glycemic index and some physicochemical properties of starch and flour from common bean (Phaseolus vulgaris L.) varieties grown in Canada. Food Res Int 41: 869-875.

4 Alfenas RCG, Mattes RD (2005) Influence of glycemic index/load on glycemic response, appetite, and food intake in healthy humans. Diabetes Care 28: 2123-2129.

5 Bharath Kumar S, Prabhasankar P (2015) A study on noodle dough rheology and product quality characteristics of fresh and dried noodles as influenced by low glycemic index ingredient. J Food Sci Tech 52: 1404-1413.

6 Association of Official Analytical Chemists (AOAC) (2007) Official methods of analysis, Washington, DC, USA.

7 Wolever TMS, Jenkins DJA, Jenkins AL, Joss RG (1991) The glycemic index: methodology and clinical implications. Am J Clin Nutr 54: 846-854.

8 Winer BJ (1971) Statistical principles in experimental design. ( $2^{\text {nd }}$ eds) McGraw-Hill, New York.

9 Duncan BD (1955) Multiple range and multiple F-tests. Biometrics 11: 1-42.

10 Tepper BJ, Seldner AC (1999) Sweet taste and intake of sweet foods in normal pregnancy and pregnancy complicated by gestational diabetes mellitus. Am J Clin Nutr 70: 277-284.

11 Graham F, Neil KA, John BE (2007) Liking vs. wanting food: importance for human appetite control and weight regulation. Neur Biobehav $R$ 31: 987-1002.

12 Liese AD, Schulz M, Fang F, Wolever TMS, Agostino RB et al. (2005) Dietary glycemic index and glycemic load, carbohydrate and fiber intake, and measures of insulin sensitivity, secretion, and adiposity in the insulin resistance atherosclerosis study. Diabetes Care 28: 2832-2838.

13 Dilawari JB, Kamath PS, Batta RP, Mukewar S, Raghavan S (1981) Reduction of postprandial plasma glucose by bengal gram dal (Cicerarietnum) and rajmah (Phaseolus vulgaris). Am J Clin Nutr 34: 2450-2453.
14 Khan TN, Zanvar VS, Nerlekar JP, Devi R (2009) Glycemic index of developed therapeutic foods. Asian J Home Sci 4: 246-248.

15 Porwal VB, Bharath Kumar S, Madhumathi R, Prabhasankar P (2014) Influence of health based ingredient and its hydrocolloid blends on noodle processing. J Food Measure 8: 283-295.

16 Johnson JK, Thomas SJ, Hall RS (2005) Palatability and glucose, insulin and satiety responses of chickpea flour and extruded chickpea flour bread eaten as part of a breakfast. Eur J Clin Nutr 59: 169-176.

17 Salmeron J, Ascherio A, Rimm EB, Colditz GA, Spiegelman D et al. ( 1997) Dietary fiber, glycemic load, and risk of NIDDM in men. Diabetes Care 20: 545-550.

18 Brennan CS, Blake DE, Ellis PR, Schofield JD (1996) Effects of guar galactomannan on wheat bread microstructure and on the in vitro and in vivo digestibility of starch in bread. J Cereal Sci 24: 151-160.

19 Hawkins A, Johnson SK (2005) In vitro carbohydrate digestibility of whole-chickpea and chickpea bread products. Int J Food Sci Nutr 56: 147-155.

20 Wolever TM, Bolognesi C (1996) Prediction of glucose and insulin responses of normal subjects after consuming mixed meals varying in energy, protein, fat, carbohydrate and glycemic index. J Nutr 126: 2807-2812.

21 Larsen TM, Dalskov S, Baak M, Jebb SA, Papadaki A et al. (2010) Diets with high or low protein content and glycemic index for weight-loss maintenance. New Eng J Med 363: 2102-2113.

22 Chandalia M, Garg A, Lutjohann D, Bergmann K, Grundy SM et al. (2000) Beneficial effects of high dietary fiber intake in patients with type 2 diabetes mellitus. New Eng J Med 342: 1392-1398.

23 Montonen J, Knekt P, Jarvinen R, Aromaa A, Reunanen A (2003) Whole-grain and fiber intake and the incidence of type 2 diabetes. Am J Clin Nutr 77: 622-629.

24 Glycemic Load definition

25 Villegas R, Liu S, Gao Y, Yang G, Li H (2007) Prospective study of dietary carbohydrates, glycemic index, glycemic load, and incidence of type 2 diabetes mellitus in middle-aged chinese women. Arch Internal Med 167: 2310-2316.

26 Ahmed MB, Hamed RA, Ali ME, Hassan AB, Babiker EE (2006) Proximate composition, antinutritional factors and protein fractions of guar gum seeds as influenced by processing treatments. Pak J Nutr 5: 481-484.

27 Willett W, Manson J, Liu S (2002) Glycemic index, glycemic load, and risk of type 2 diabetes. Am J Clin Nutr 76: 274S-280S. 